Science Archives (2020) Vol. 1 (2), 50-52

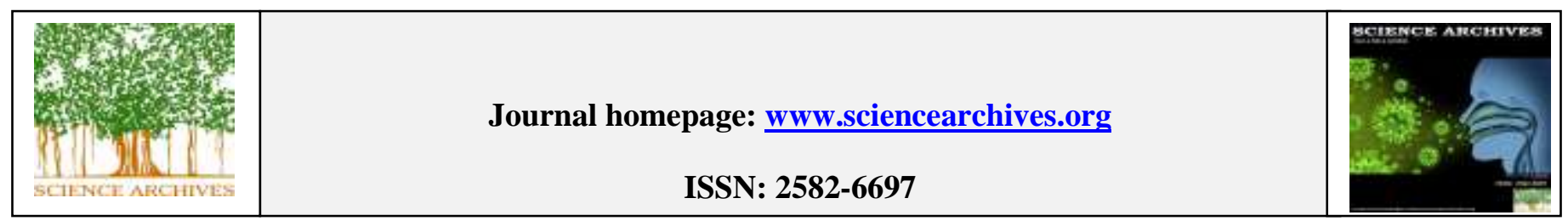

Research Article

http://dx.doi.org/10.47587/SA.2020.1201

\title{
Value addition of jackfruit through production of chips
}

\author{
T. Uma Maheswari* and Vidhu Valsan \\ Department of Horticulture, Faculty of Agriculture, Annamalai University, Annamalainagar-608 002. \\ *Corresponding author: umahorti2003@gmail.com
}

Received: Feb 5, 2020 / Accepted: Aug 8, 2020/ Published: Sept 29, 2020

\begin{abstract}
An investigation was carried out to process jackfruit chips with four formulations and five replications in a Completely Randomized Design ( T1- 3.2 \%,T2- $2.8 \%$, T3- $2.4 \%$, T4- $2 \%$ of salt concentration). The effect of the processing on the nutritional quality and sensory quality of the chips made out of jackfruit were determined. Storage life and cost economics were also calculated in this study. The sensory evaluation was carried out monthly for a period of six months during storage. Among the formulations, T4 formulated with $2.0 \%$ of salt concentration was analyzed as the best formulation with maximum period of shelf life (4 months) over other formulations and the least values for oil content and carotenoids $(33.89 \%$ and $0.32 \mathrm{mg} / 100 \mathrm{~g}$ respectively) and the moisture content of $4.75 \%$. Sensory scores for taste (8.7) and overall acceptability (8.8) were also maximum in T4 during initial sensory evaluation. The other sensory parameters like colour (8.8), flavor (8.0), and crispness (8.0) were maximum in $\mathrm{T} 2$ formulated with $2.8 \%$ of salt concentration and this was followed by $\mathrm{T} 4$ which secured the next best scores. Cost of production of $1 \mathrm{~kg}$ of chips was also estimated with the benefit cost ratio of 2.00 .
\end{abstract}

Keywords: Jack Fruit, Chips, Value addition

\section{Introduction}

As there is problem of malnutrition exists in the world, fruits are the excellent food supplements with vitamins and antioxidants. Processing of fruits is a boon of science and technology with multiple benefits. For developing countries like India fruit processing has bright scope. Proper post harvest handling practices reduce the postharvest losses of fruit produces. Jackfruit is being valued by the processors to make best use of the heaps of the fruit that glut the market during harvesting seasons. Moreover, the color, texture, pleasant smell and taste make the fruit highly suitable for processing and value addition. Hence an experiment was conducted to study the production and quality evaluation of jackfruit chips.

\section{Methods and Materials}

The present investigation on preparation of jackfruit chips was carried out in the Post Harvest Laboratory of Department of Horticulture, Faculty of Agriculture,
Annamalai University, Annamalai Nagar. This investigation was carried out to process jackfruit chips with four formulations and five replications in a Completely Randomized Design ( T1- $3.2 \%, \mathrm{~T} 2-2.8 \%$, T3- $2.4 \%$, T4$2 \%$ of salt concentration). The effect of the processing on the nutritional quality and sensory quality of the chips made out of jackfruit were determined. Storage life and cost economics were also calculated in this study.

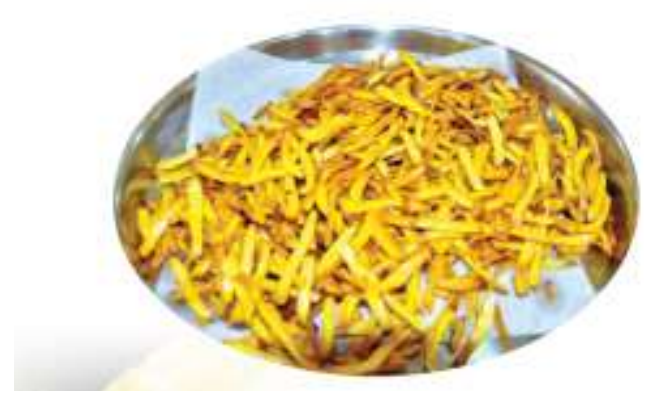

Fig. 1. Jackfruit chips 
The sensory evaluation was carried out monthly for a period of six months during storage. Matured, un-ripened jackfruit bulbs were used for the preparation of Jackfruit chips. Seeds were removed from the bulbs and the bulbs were cut into shreds of 0.5 to $0.6 \mathrm{~cm}$ width, and the length was maintained as much as the bulb. The pieces were blanched in the boiling water. Salt was added for two minutes and allowed to drain completely. On a frying pan oil was heated and fried the chips. 1-2 spoons of salt water were also added in oil while frying. Collection of water samples.

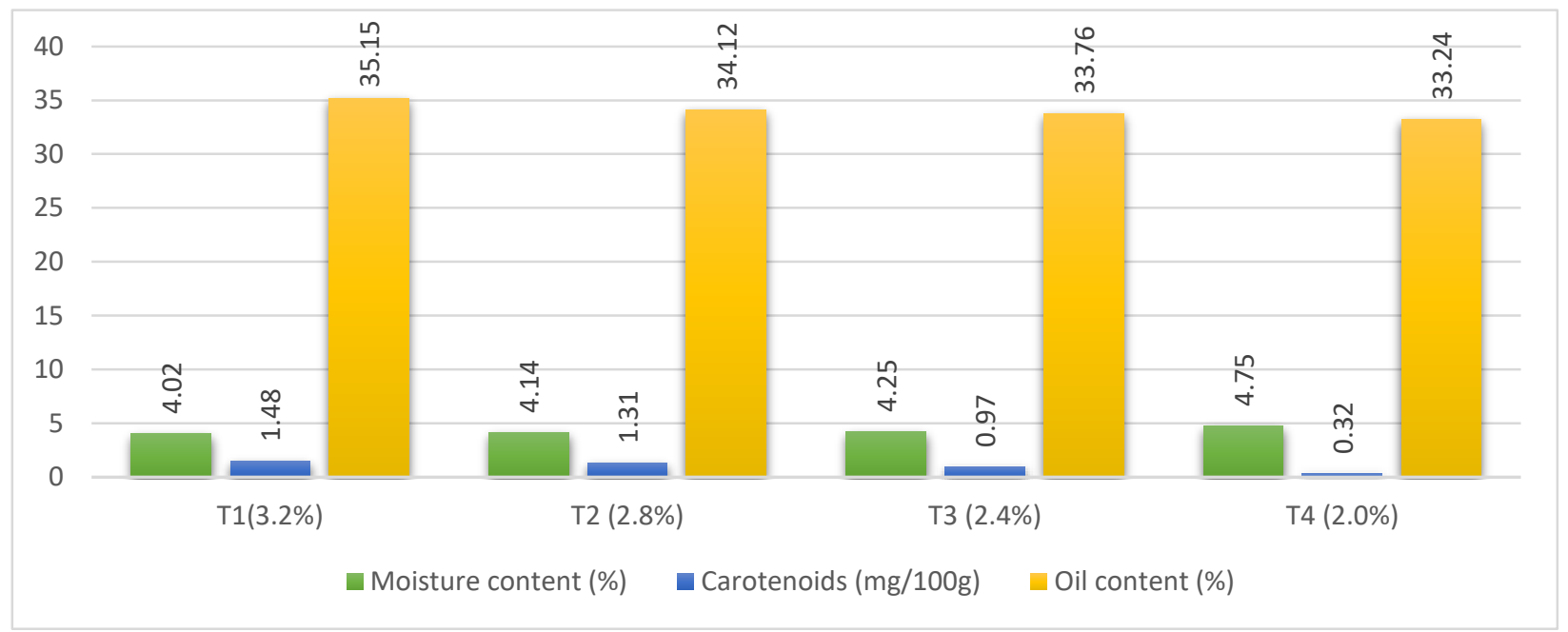

Fig. 2. Effect of variation in Salt concentration on Nutritional quality of Jackfruit Chips

$\mathrm{T}_{1}-3.2 \%$ of salt concentration; $\mathrm{T}_{3}-2.4 \%$ of salt concentration

$\mathrm{T}_{2}-2.8 \%$ of salt concentration; $\mathrm{T}_{4}-2.0 \%$ of salt concentration

Table 1. Sensory Scoring for Jackfruit Chips at $4^{\text {th }}$ Month of Evaluation

\begin{tabular}{|c|c|c|c|c|c|c|c|c|c|c|c|c|c|c|c|c|c|c|c|c|}
\hline \multicolumn{6}{|c|}{$T_{1}(3.2 \%$ of salt $)$} & & & \multicolumn{3}{|c|}{$\mathrm{T}_{2}(2.8 \%$ of salt $)$} & \multicolumn{5}{|c|}{$\mathrm{T}_{3}(2.4 \%$ of salt $)$} & \multicolumn{5}{|c|}{$\mathbf{T}_{4}(2.0 \%$ of salt $)$} \\
\hline $\begin{array}{l}\text { Taste } \\
\text { panel } \\
(\mathrm{TP}) \mathrm{s}\end{array}$ & 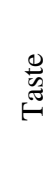 & $\frac{3}{0}$ & $\begin{array}{l}\vdots \\
\overline{0} \\
\frac{\vec{I}}{I}\end{array}$ & 岂 & 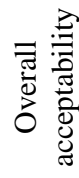 & $\underset{\mathbb{E}}{\mathbb{E}}$ & $\frac{\bar{\partial}}{0}$ & 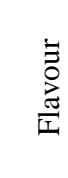 & $\begin{array}{l}\tilde{0} \\
\tilde{0} \\
\stackrel{\tilde{J}}{\Xi}\end{array}$ & 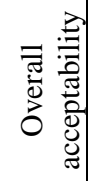 & 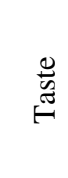 & $\frac{\bar{z}}{0}$ & $\begin{array}{l}\vdots \\
\bar{\Xi} \\
\frac{\vec{J}}{I}\end{array}$ & 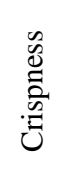 & 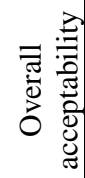 & 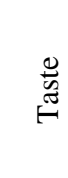 & $\frac{0}{0}$ & $\begin{array}{l}\vdots \\
\frac{\Xi}{I} \\
\end{array}$ & $\begin{array}{l}\tilde{\Delta} \\
\stackrel{0}{0} \\
: \tilde{U} \\
\tilde{U}\end{array}$ & 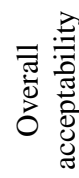 \\
\hline TP1 & - & - & - & - & - & 3.0 & 4.0 & 3.0 & 3.0 & 3.0 & 4.0 & 3.0 & 3.0 & 4.0 & 4.0 & 6.0 & 6.0 & 5.0 & 5.0 & 7.0 \\
\hline TP2 & - & - & - & - & - & 5.0 & 5.0 & 5.0 & 4.0 & 4.0 & 4.0 & 3.0 & 3.0 & 4.0 & 5.0 & 7.0 & 5.0 & 5.0 & 7.0 & 6.0 \\
\hline TP3 & - & - & - & - & - & 4.0 & 5.0 & 4.0 & 4.0 & 4.0 & 3.0 & 4.0 & 5.0 & 3.0 & 5.0 & 6.0 & 5.0 & 6.0 & 6.0 & 5.0 \\
\hline TP4 & - & - & - & - & - & 4.0 & 5.0 & 4.0 & 4.0 & 5.0 & 3.0 & 4.0 & 5.0 & 5.0 & 5.0 & 4.0 & 6.0 & 5.0 & 6.0 & 5.0 \\
\hline TP5 & - & - & - & - & - & 5.0 & 4.0 & 3.0 & 3.0 & 5.0 & 4.0 & 5.0 & 5.0 & 4.0 & 3.0 & 6.0 & 7.0 & 7.0 & 7.0 & 7.0 \\
\hline TP6 & - & - & - & - & - & 5.0 & 4.0 & 3.0 & 4.0 & 4.0 & 3.0 & 4.0 & 3.0 & 5.0 & 5.0 & 5.0 & 6.0 & 5.0 & 5.0 & 6.0 \\
\hline TP7 & - & - & - & - & - & 4.0 & 3.0 & 5.0 & 5.0 & 5.0 & 5.0 & 5.0 & 4.0 & 5.0 & 5.0 & 6.0 & 6.0 & 6.0 & 5.0 & 5.0 \\
\hline TP8 & - & - & - & - & - & 5.0 & 4.0 & 4.0 & 5.0 & 3.0 & 4.0 & 5.0 & 5.0 & 4.0 & 3.0 & 7.0 & 5.0 & 6.0 & 6.0 & 7.0 \\
\hline TP9 & - & - & - & - & - & 3.0 & 3.0 & 5.0 & 4.0 & 5.0 & 5.0 & 5.0 & 5.0 & 3.0 & 4.0 & 7.0 & 5.0 & 5.0 & 5.0 & 6.0 \\
\hline TP 10 & - & - & - & - & - & 3.0 & 3.0 & 4.0 & 4.0 & 3.0 & 5.0 & 3.0 & 3.0 & 4.0 & 5.0 & 6.0 & 7.0 & 7.0 & 5.0 & 5.0 \\
\hline $\begin{array}{c}\text { Grand } \\
\text { Total }\end{array}$ & - & - & - & - & - & $\begin{array}{c}41 . \\
0\end{array}$ & 40.0 & 40.0 & 40.0 & 41.0 & 40.0 & 41.0 & 41.0 & 41.0 & 44.0 & 60.0 & 58.0 & $\mathbf{5 7 . 0}$ & $\mathbf{5 7 . 0}$ & 59.0 \\
\hline Average & - & - & - & - & - & 4.1 & 4.0 & 4.0 & 4.0 & 4.1 & 4.0 & 4.1 & 4.1 & 4.1 & 4.4 & 6.0 & 5.8 & 5.7 & 5.7 & 5.9 \\
\hline
\end{tabular}




\section{Results and Discussion}

The results revealed that among the formulations, T4 formulated with $2.0 \%$ of salt concentration was analysed as the best formulation with maximum period of shelf life (4 months) over other formulations and the least values for oil content and carotenoids (33.89 \% and $0.32 \mathrm{mg} / 100 \mathrm{~g}$ respectively) and the moisture content of $4.75 \%$. Sensory scores for taste (8.7) and overall acceptability (8.8) were also maximum in T4 during initial sensory evaluation. The other sensory parameters like colour (8.8), flavour (8.0), and crispness (8.0) were maximum in $\mathrm{T} 2$ formulated with $2.8 \%$ of salt concentration and this was followed by $\mathrm{T} 4$ which secured the next best scores. Cost of production of $1 \mathrm{~kg}$ of chips was also estimated with the benefit cost ratio of 2.00 .

When chips from different formulation with variation in salt concentration were tested for storage stability, all the organoleptic quality parameters (colour, crispness, flavor, taste and overall acceptability) showed a decreasing trend concomitant with storage period for all the treatment( Table 1). In this present study, T4, formulated with $2.0 \%$ of salt concentration was analyzed as the best formulation (Fig.1) with maximum period of shelf life over other formulations and the least values for oil content and carotenoids (33.89\% and $0.32 \mathrm{mg} / 100 \mathrm{~g}$ respectively). The moisture content was observed as $4.75 \%$ in T4. As the concentration of salt increases, the absorption tendency of oil gets reduced, but the carotenoids gradually increased. Similar findings were observed in Shobha and Bharadhi (2010) in a study conducted in value addition to ber through pickle formations. Sensory scores for taste (8.7) and overall acceptability (8.8) were also maximum in T4 during initial sensory evaluation. The other sensory parameters like colour (8.8), flavour (8.0), and crispness (8.0) were maximum in T2 formulated with $2.8 \%$ of salt concentration. Colour is most representative index of chips quality (Lisinska and Leszczynski, 1989). The decrease in score for colour of jackfruit chips with time in storage might be due to oxidation and bleaching of carotenoids in the presence of oxygen (Rico et al., 2007). Crispness of chips is related to their moisture content and it decreased due to increase in moisture content of chips during storage. The critical moisture for crispness of banana chips is 5\%, and above which the quality is affected (Shere et al., 1993). Moisture content of ideal potato chips is $2 \%$ (Lisinska and Leszczynski, 1989). Comparing the moisture content and sensory score for crispness of the jackfruit chips, it was clear that the chips were more acceptable only up to $5 \%$ moisture. The taste of the chips was influenced by the salt level, biochemical constitution of the genotype and rancidity caused during storage. Better taste in chips of different formulations might varying due to better infusion of salt in chips along with favourable biochemical characteristics of bulbs (Satishkumar, 2014). T4 (2\% of salt) showed maximum shelf life of five months due to the optimum moisture content when compared to the formulations. Benefit cost ratio of jackfruit chips production was 2.00. It is highly favourable to take this value addition activity and therefore, this processing can be recommended for commercial exploitation. Hence it is concluded that, among the formulations, T4 formulated with $2.0 \%$ of salt concentration was analyzed as the best formulation with maximum period of shelf life (4 months) over other formulations.

\section{Conflict of Interest}

Authors hereby declare no conflict of interest.

\section{References}

Lisinska, G. and Leszczynski, W. (1989) Potato tubers as a raw material for processing and nutrition. Potato science and technology, 11(2): 113-116.

Rico, D., Martin-Diana, A.B., Barat, J.M. and Barry-Ryan, C. (2007). Extending and measuring the quality of fresh-cut fruit and vegetables: a review. Trends in Food Science \& Technology, 18(7): 373-386.

Satishkumar, S. (2014) Studies on Jackfruit (Artocarpus heterophyllus Lam.) Chips production and its storage. M. Tech. (Agricultural Engineering), Thesis, University of Agricultural Sciences, Bangalore.

Shere, D.M., Kotapalle S.L., and Kulkarni, D.N. (1993) Effect of Maturity Stage on Qualities Fried Banana Chips. Journal of Maharashtra Agricultural Universities, 18(3): 338-338.

Shobha D, Bharati, P. (2010) Value addition to Ber (Zyziphus mauritiana Lam.) through preparation of pickle. Karnataka Journal of Agricultural Sciences, 20 (2): 3213.

How to cite this article:

Maheshwari T.U. and Valsan, V.(2020) Value addition of jackfruit through production of chips. Science Archives, Vol. 1 (2): 50-52. http://dx.doi.org/10.47587/SA.2020.1201

This work is licensed under a Creative Commons Attribution 4.0 International License.

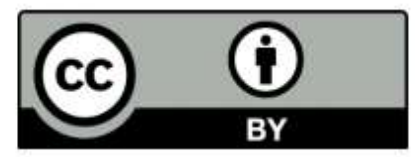

